\title{
Diagnóstico e prognóstico sobre o tratamento de resíduos sólidos do programa Coleta Seletiva do município de Esteio-RS, em uma cooperativa de reciclagem
}

\author{
Sydney Sabedot, Daniel Augusto Anton* \\ JULIANA KOETZ* \\ sydney.sabedot@unilasalle.edu.br
}

\begin{abstract}
Resumo
A Lei Federal 12.305/2010 promulgou a Política Nacional de Resíduos Sólidos, descrevendo as diretrizes para gestão integrada e gerenciamento de resíduos sólidos e responsabilidades do poder público. A Prefeitura Municipal de Esteio-RS vem ampliando a coleta de resíduos no programa Coleta Seletiva, gerando aumentos de massa de resíduos para reciclagem. Os resíduos são destinados à Cooperativa de Trabalhadores da Reciclagem de Esteio, que recicla e vende os materiais. A cooperativa precisa estar adequada quanto a equipamentos e operações para tratar a crescente massa e manter conexão com os objetivos do programa. Para se conhecer a realidade acerca dos equipamentos e operações da cooperativa e perceber seu potencial para atender as demandas futuras do Coleta Seletiva, realizou-se um estudo sobre diagnóstico operacional, que resultou no prognóstico com sugestões para melhorar suas operações. O estudo identificou diversos problemas na infraestrutura predial, na manutenção de máquinas e equipamentos, nos processos de triagem e nos fluxos operacionais. Assim, a cooperativa já opera com dificuldades para atender a demanda atual. Sem reestruturação não terá condições para receber o aumento de demanda do Coleta Seletiva. Este artigo relata os resultados do diagnóstico operacional realizado na COOTRE e faz o prognóstico com recomendações para a sua reestruturação.

Palavras Chave: diagnóstico operacional, reciclagem, resíduos sólidos.
\end{abstract}

\section{Diagnosis and prognosis about the treatment of solid waste at Selective Collection program in the city of Esteio-RS, in a cooperative recycling.}

\begin{abstract}
The Federal Law 12305/2010 promulgated the National Policy on Solid Waste, describing the guidelines for the integrated management and the management of solid waste and the government's responsibilities in this process. The Esteio City Hall has been progressively expanding the collection of solid waste in its Selective Collection Program, which causes increases in mass of waste for recycling. The solid waste is sent to the Cooperativa de Trabalhadores da Reciclagem de Esteio, which makes the separation and sale of materials. The cooperative must be adequate in terms of equipment and operations to treat the growing mass of waste and maintain connection with the objectives of that program. A study was developed to know the reality of both equipment and operational processes of the cooperative and thus observe their potential to receive future
\end{abstract}

${ }^{*}$ Centro Universitário La Salle - UNILASALLE 
demands of the Selective Collection Program. This study resulted prognosis with suggestions for optimizing their operations. There are several problems in building infrastructure, maintenance of machinery and equipment, waste treatment and operational flows. Under these conditions, the cooperative already have difficulties to treat the current demand. Without restructuring it will not be able to receive future increase in waste from the Selective Collection Program.

key words: operational diagnosis, recycling, solid waste.

\section{INTRODUÇÃO}

$\mathrm{E}$ ste artigo apresenta o diagnóstico sobre atividades de tratamento de resíduos sólidos do programa Coleta Seletiva da Prefeitura Municipal de Esteio-RS (PME), realizado na Cooperativa de Trabalhadores da Reciclagem de Esteio (COOTRE), RS. As entidades têm parceria voltada para o gerenciamento de resíduos sólidos do município, em atendimento à Lei Federal 12.305/2010. O diagnóstico foi realizado com o objetivo de se conhecer a realidade do fluxo das atividades operacionais e apontar suas deficiências, as dificuldades que os cooperados têm nas operações de reciclagem, bem como sugerir um prognóstico para que as operações e o fluxo operacional sejam compatíveis com os planos da PME em ampliar o programa Coleta Seletiva, o que não ocorre na atualidade.

O município de Esteio localiza-se no vale do rio dos Sinos, na região da Grande Porto Alegre, no estado do Rio Grande do Sul. Seu território tem $27.7 \mathrm{~km}^{2}$ e sua população é estimada em 84 mil habitantes (IBGE, 2015). O programa Coleta Seletiva, desenvolvido pela Secretaria Municipal de Meio Ambiente de Esteio (SMMA), visa à coleta de vidros, plásticos, metais, papeis e eletrônicos, e sua destinação à COOTRE, uma cooperativa de trabalhadores que realiza operações de reciclagem e comercialização desses materiais. Atualmente, a coleta seletiva atende cerca de 3\% da coleta necessária para o município. Para atender a legislação ambiental, a PME vem promovendo ações para ampliar a coleta e otimizar os processos de reciclagem dos resíduos sólidos. Uma das ações é a adequação das operações de reciclagem na COOTRE, que atualmente são deficientes e devem ser melhoradas para atenderem as necessidades do município. O presente diagnóstico é parte deste processo.

A COOTRE opera no Centro de Triagem de Esteio, inaugurado em 2003, em uma área de $20.400 \mathrm{~m} 2$. A área é compartilhada com o Departamento de Arborização do município, o Projeto Confeccionando Sonhos, uma ação social municipal, e o Canil Municipal de Esteio. À época, denominava-se Associação dos Recicladores e Catadores de Esteio e era constituída por oito mulheres que reciclavam cerca de oito toneladas mensais de resíduos sólidos e geravam renda mensal média individual em torno de R\$ 80,00. Em 2005, a PME implantou o programa Coleta Seletiva, que cobria cerca de 30\% do território de Esteio. Em 2013, a SMMA iniciou uma série de programas para a conscientização ambiental da população, e a massa de resíduos sólidos para reciclagem na cooperativa aumentou para cerca de $84 \mathrm{t}$ mensais, o número de cooperados, entre homens e mulheres, aumentou para 29 e a renda mensal média individual aumentou para cerca de R\$ 1.300,00 (PROCHNOW \& ROSSETTI, 2010; ANTON, 2014).

De acordo com a ABNT NBR 10004:2004, resíduos sólidos constituem resíduos nos estados sólido e semissólido, os quais resultam de atividades de origem industrial, doméstica, hospitalar, comercial, agrícola, de serviços e de varrição. Neste conceito estão incluídos lodos de sistemas de tratamento de água e de instalações de controle de poluição, bem como líquidos cujas particularidades tornem inviável o seu lançamento na rede de esgotos ou corpos de água. A COOTRE recebe resíduos sólidos domésticos, comerciais, industriais e hospitalares (assépticos) provenientes do programa Coleta Seletiva, da SMMA.

A Lei Federal 12.305/2010 institui a Política Nacional de Resíduos Sólidos, dispondo sobre seus princípios, objetivos e instrumen- 
tos, bem como as diretrizes relativas à gestão integrada e ao gerenciamento de resíduos sólidos, às responsabilidades dos geradores e do poder público e aos instrumentos econômicos aplicáveis. Deve ser observada por pessoas físicas ou jurídicas, de direito público ou privado, responsáveis direta ou indiretamente pela geração de resíduos sólidos, incluindo as que desenvolvem ações para gestão integrada ou gerenciamento de resíduos sólidos. Esta Lei cita várias definições: resíduos sólidos - material, substância, objeto ou bem descartado resultante de atividades humanas em sociedade, a cuja destinação final se procede nos estados sólido ou semissólido; gerenciamento de resíduos sólidos - conjunto de ações exercidas nas etapas de coleta, transporte, transbordo, tratamento e destinação final ambientalmente adequada dos resíduos sólidos, de acordo com o plano municipal de gestão integrada de resíduos sólidos, ou com o plano de gerenciamento de resíduos sólidos, exigidos na forma desta Lei; coleta seletiva - coleta de resíduos sólidos previamente segregados conforme sua constituição ou composição; logística reversa instrumento de desenvolvimento econômico e social caracterizado por um conjunto de ações, procedimentos e meios destinados a viabilizar a coleta e a restituição dos resíduos sólidos ao setor empresarial, para reaproveitamento; reciclagem - processo de transformação dos resíduos sólidos que envolve a alteração de suas propriedades físicas, físico-químicas ou biológicas, com vistas à transformação em insumos ou novos produtos; rejeitos - resíduos sólidos que, depois de esgotadas todas as possibilidades de tratamento e recuperação por processos tecnológicos disponíveis e economicamente viáveis, não apresentem outra possibilidade que não a disposição final ambientalmente adequada.

O termo diagnóstico refere-se ao diagnóstico operacional citado por ARAÚJO (1998) e que, neste artigo, consiste em um processo de avaliação e descrição das atividades de reciclagem de resíduos sólidos em desenvolvimento na COOTRE. Os principais benefícios deste processo para a entidade são: dar ciência sobre a atual situação das operações; obter uma avali- ação neutra com observações externas; identificar ajustes e alternativas operacionais; possibilitar implantação de melhores práticas operacionais (ARAÚJO, 1998). E o termo prognóstico refere-se à proposição de ações com vistas a melhorias dos processos operacionais da cooperativa, tendo como base os resultados do diagnóstico operacional.

Segundo NASCIMENTO et al. (2011), a avaliação de desempenho das organizações é uma atividade fundamental na gestão empresarial atual, trazendo novos desafios aos gestores ante a dinâmica no mundo dos negócios. Vários autores tratam da avaliação de desempenho, sobretudo quanto aos indicadores de desempenho organizacional (CALLADO et al., 2008; MENEZES et al., 2008; KARDEC et al., 2009; BANDEIRA, 2010; SIQUEIRA, 2010; MÜLLER, 2014). COSTA \& JARDIM (2010) propõem modelos de diagnóstico operacional baseados em categorias de indicadores de eficácia, eficiência, qualidade, produtividade e efetividade. Os indicadores de desempenho são importantes na gestão de um processo e sua utilização resulta em tomadas de decisão mais objetivas, otimização de processos e melhoria nos resultados. Na prática, a dimensão da avaliação de desempenho vai depender do tamanho e da natureza da organização. Com relação à COOTRE, a entidade é uma cooperativa com baixo controle operacional e gerencial, cujas operações foram se sucedendo com um mínimo de organização e um planejamento incipiente. Neste contexto, o estudo realizado na entidade foi uma primeira tentativa para mostrar os problemas e propor soluções operacionais de modo a tornar o processo de gestão mais organizado.

O gerenciamento de resíduos sólidos tem sido uma preocupação que ultrapassa a fronteira das exigências legais. A obrigação que os municípios têm para elaborarem seus Planos Municipais de Resíduos Sólidos, estabelecida em lei, vem contagiando empreendedores e a população em geral, que se mostram solidários na tentativa de minimizar os impactos ambientais provocados pelo consumo da sociedade atual. Inúmeros foram os encontros internacio- 
nais e tentativas para frear o consumo, desde o histórico Clube de Roma, fundado em 1968, e que em 1972 publicou o relatório Limites do Crescimento, que estimulava, entre outras ações, um consumo baseado nas necessidades básicas das pessoas. Além de polêmicos e com pouca sustentação científica, esses relatórios e prognósticos catastrofistas, via de regra, vêm se mostrando exagerados e equivocados, porque suas previsões não vêm se concretizando ao longo do tempo. Por isso, felizmente, seus modelos também vêm sendo sepultados na vala comum do esquecimento. Muito mais eficaz têm sido os projetos de conscientização ambiental para a sociedade, que passa a se engajar e colaborar de modo mais assíduo e voluntário nos programas de gestão de resíduos das administrações municipais.

No Brasil, o cenário da reciclagem de resíduos sólidos envolve o trabalho de indivíduos que compõem as camadas mais pobres da população, os quais encontram na catação de resíduos sólidos um modo de vida que lhes proporcionam, às vezes, a única oportunidade para obterem uma fonte de rendimento. No entanto, na atualidade, o trabalho individual na catação/reciclagem já não traz tanta atratividade econômica. Para VIEIRA et al. (2013) e SILVA et al. (2009), um modelo mais eficaz no combate à pobreza e uma possível solução para a questão do lixo passa pelas associações e cooperativas de reciclagem de resíduos sólidos.

Para LIMA \& HORÁCIO (2015), as principais ações para o sucesso de uma cooperativa de reciclagem de lixo são: apoio administrativo e contábil, com contratação de profissional responsável pela gestão da cooperativa; criação de serviço social, com a atuação de assistentes sociais junto aos catadores; fornecimento de uniformes e equipamentos de proteção individual e coletiva; implantação de atividades de caráter educativo, como cursos de alfabetização e programas de educação ambiental. O suporte técnico-operacional pode ser acrescentado a estas ações, considerando a expectativa de aumento de demanda em curto/médio prazos e a consequente necessidade de otimizar processos e incorporação de tecnologias mais apropriadas.

A pesquisa sobre o tema em pauta teve início nas relações acadêmicas entre os autores deste artigo, em suas atividades de orientação de alunos e realização de estudos para trabalho de conclusão de curso de graduação (Geografia) e dissertação de mestrado acadêmico (Avaliação de Impactos Ambientais), ambos no Unilasalle. A COOTRE foi escolhida, porque um dos autores deste artigo trabalha na SMMA e, ao dar suporte socioeducativo aos cooperados da entidade, verificou dificuldades nas operações que foram relatadas pelos mesmos. Estas relações favoráveis proporcionaram acesso irrestrito às operações, aos dados de produção e aos relatos dos cooperados sobre suas dificuldades nas rotinas diárias, condições que foram fundamentais para o êxito da pesquisa.

\section{Metodologia}

O estudo compreendeu duas etapas: diagnóstico operacional e prognóstico operacional. O diagnóstico operacional foi realizado em 10 dias de visitas à COOTRE, cada uma correspondendo a dois turnos (manhã e tarde) de observações. Neste período, observaram-se todas as operações, desde a chegada dos resíduos sólidos nos caminhões que atuam na coleta seletiva municipal, até a entrega das matérias-primas comercializadas, após beneficiamento. Inicialmente, traçou-se o fluxograma operacional. $\mathrm{Na}$ sequência, em cada etapa dos processos foram feitas observações sistemáticas e registros por escrito em caderneta e por fotografia, quanto às técnicas e o modo como os cooperados trabalhavam. Concomitantemente, registrou-se, também em caderneta, o relato informal dos cooperados quanto às suas impressões acerca das operações, dificuldades, críticas e sugestões para melhorias no ambiente operacional que levassem ao aumento de produtividade, ganhos financeiros e qualidade nas condições de trabalho e saúde. Além disso, a administração da cooperativa disponibilizou planilhas de controle sobre resíduos recebidos, processados, produzidos e comercializados, bem como forneceu informações sobre receitas, compra- 
dores, parceiros no negócio, modelo organizacional da cooperativa e rotinas administrativas gerais, entre outras. Neste diagnóstico serão abordadas apenas as questões operacionais da reciclagem de resíduos sólidos na COOTRE.

O prognóstico operacional consistiu em propor sugestões para as operações de tratamento, as quais deverão melhorar as rotinas operacionais e possibilitarão o aumento da massa de resíduos a ser tratada, de acordo com os objetivos da SMMA em ampliar a coleta de resíduos do programa Coleta Seletiva no município de Esteio. As sugestões fundamentaram-se em diversas referências: visitas a entidades congêneres que possibilitaram observações de experiências bem-sucedidas (Acrer, Cooarlas e U.T. Arevipa); vídeos de operações similares disponíveis na Internet (COOPERCATA, 2015; PROJETO CRIAR, 2015; 100 DIMENSÃO, 2015; COORETA, 2015; WAIG, 2015); fontes bibliográficas diversas, como relatórios de instituições governamentais, experiências relatadas em artigos científicos, periódicos, congressos e material acadêmico em dissertações de mestrados (HEIDEN, 2008; SANTOS et. al., 2009; COSTA \& JARDIM, 2010; ITCP-FGV, 2012; INSTITUTO 5 ELEMENTOS, 2014; BRASKEM, 2015). Nessas referências buscaram-se modelos, informações e fatos que apontavam operações ideais no trato dos resíduos sólidos. É importante salientar que não existe um modelo operacional específico, porque existem modelos operacionais muito diferenciados entre si, os quais resultam de características distintas, como a natureza dos resíduos, a dimensão da entidade, a massa mensal de resíduos tratados, a disponibilidade de tecnologias e a quantidade de equipamentos das entidades, entre outras. Para o caso específico da COOTRE, optou-se por um prognóstico operacional compatível com a estrutura montada no local, considerando suas limitações e seu potencial para melhoramentos, para tornála mais eficaz e consonante com suas próprias características.

\section{Resultados E Discussão}

\section{Diagnóstico operacional}

A sede da COOTRE possui uma área total coberta de $1.163 \mathrm{~m}^{2}$ e um pavilhão de apoio com $70 \mathrm{~m}^{2}$, este último contendo escritório, refeitório, vestiário e banheiros para os cooperados. A área e os prédios são concedidos através de um contrato de comodato com a PME, firmado por 10 anos, possibilitando que a cooperativa receba recursos financeiros e faça financiamentos, empréstimos e investimentos.

Além da área física disponibilizada, a administração municipal complementa mensalmente a renda dos cooperados, a título de serviços prestados, e responsabiliza-se por vários custos e despesas, como fornecimento de três caminhões, salários de três motoristas, manutenção dos caminhões, água, luz e telefone. A melhoria nos processos operacionais visa, também, dar maior autonomia financeira à cooperativa, para diminuir a participação da administração municipal no ônus deste processo. Apresentam-se, a seguir, as particularidades do fluxo operacional na cooperativa.

\section{A chegada de resíduos sólidos}

Os caminhões da coleta seletiva levam diariamente à COOTRE, exceto aos domingos, resíduos sólidos inorgânicos coletados nas residências, no comércio varejista, nas indústrias e no Hospital Municipal do município de Esteio. Em geral, os resíduos são constituídos por papelões, plásticos, papéis, vidros diversos, garrafas de vidro, latas, garrafas PET, metais, sucatas, eletrodomésticos e peças diversas de equipamentos. Os resíduos chegam acumulados em grandes bolsas de fibra (bags) e em sacos plásticos diversos e soltos. O descarregamento ocorre em área descoberta e de modo manual pelos cooperados (Figura 1). Em dias de chuva fraca os resíduos são descarregados do mesmo modo, molhando os resíduos e os cooperados que atuam no local. Quando a chuva é intensa a operação ocorre em local coberto no pavilhão de estocagem e comercialização (Figura 2). Esta situação gera problemas, 
porque altera a continuidade do fluxo operacional e obriga os cooperados a levar os resíduos por arraste ou em seus braços até os locais de reciclagem. Como consequências, são necessários tempos adicionais para a operação e há riscos de traumas físicos aos cooperados, especialmente porque, em geral, não usam EPIs básicos, como luvas, toucas e máscaras de proteção, mas apenas vestem o uniforme em tecido de brim da cooperativa e usam calçados inadequados.

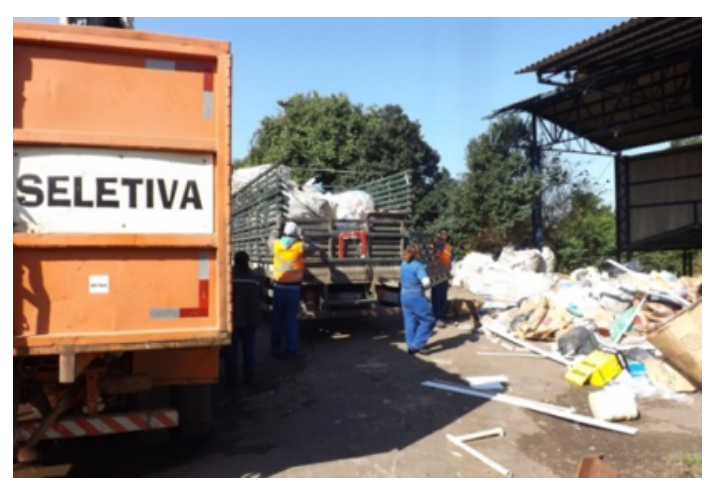

Figura 1: Descarregamento de resíduos

\section{Pré-seleção}

Após o descarregamento, os resíduos passam por uma pré-seleção que corresponde a uma triagem preliminar para separar peças de dimensões grandes e resíduos que não devem ser conduzidos à esteira de triagem, como sucatas metálicas, eletrodomésticos, papelões avulsos e cacos e garrafas de vidro. Sucatas e eletrodomésticos são estocados em local apropriado para posterior triagem e destinação diversa; cacos de vidro são armazenados em contêiner metálico, para retorno à indústria de reprocessamento; garrafas de vidro retornam às indústrias de envasamento de bebidas; papelões avulsos são amontoados em pilha ao lado do local de descarregamento, sendo conduzidos por gravidade para o nível inferior do pátio para prensagem e enfardamento. A préseleção é feita pela mesma equipe que faz o descarregamento dos resíduos e, portanto, os problemas relacionados no item anterior são os mesmos para esta operação.

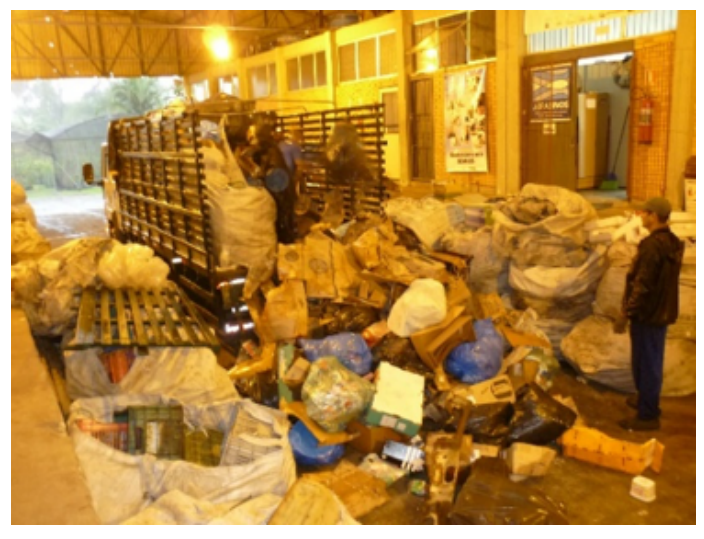

Figura 2: Descarregamento em dia de chuva

\section{Classificação na esteira}

Os resíduos acumulados nas grandes bolsas de fibra são esvaziados manualmente e, juntamente com os resíduos ensacados e soltos, são lançados em um silo-pulmão, uma estrutura em forma de funil, onde os materiais caem por gravidade sobre uma esteira prévia e são conduzidos à esteira de triagem principal. Devido à falta de manutenção, a esteira prévia está inoperante e, assim, a alimentação do funil para esta esteira, que deveria ser em fluxo contínuo, ocorre manualmente e de modo forçado, onde os cooperados forçam o fluxo dos sacos plásticos com o uso de ferramentas impróprias, como vassouras, pás e enxadas e, às vezes, com as próprias mãos até a esteira de triagem. Esta, por sua vez, só funciona de modo intermitente, com pequenos avanços mecânicos por poucos segundos, até ficar completamente abastecida em sua extensão com pilhas de resíduos para triagem, em uma operação caracterizada como sendo por batelada (Figura 3). Na sequência, com a esteira de triagem parada, 10 cooperados iniciam a triagem propriamente dita, rasgando os sacos plásticos, esvaziando-os dos resíduos, que, liberados, são catados e separados conforme sua natureza. Quando todos os resíduos são triados, nova batelada de sacos plásticos é recarregada sobre a esteira de triagem e a operação é repetida várias vezes ao longo da 
jornada de 10 horas diárias de trabalho.

Parte dos resíduos triados é descarregada em 11 dutos dispostos ao lado da esteira. Os resíduos vão se acumulando nas grandes bolsas de fibra conectadas aos dutos e dispostas sob a passarela da esteira. Entretanto, a triagem pode dar origem a cerca de 30 diferentes materiais. Como os dutos são insuficientes, parte dos resíduos triados é lançada manualmente em bolsas adicionais dispostas lateralmente à passarela da esteira (Figura 4). Quando cheias, as bolsas de fibra são retiradas e arrastadas manualmente para as prensas, ou para os boxes de armazenamento.

Resíduos que não despertam interesse econômico são deixados sobre a esteira e descarregados no piso do prédio na extremidade final da mesma. Quando há um determinado volume acumulado no piso, estes resíduos são retirados com pá e estocados em um container para descarte em aterro sanitário.

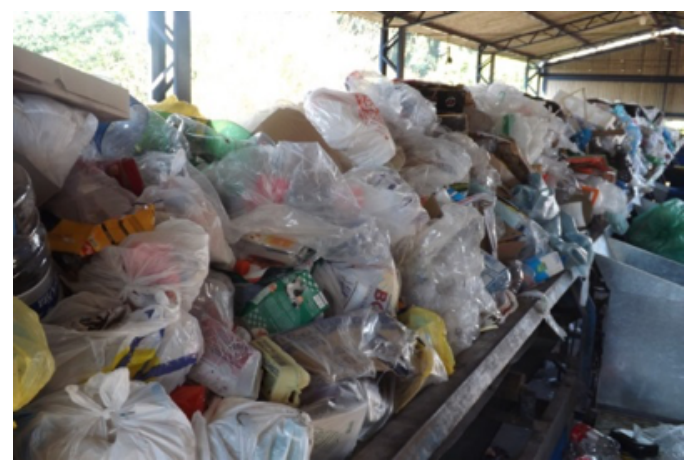

Figura 3: Esteira de triagem em operação.

Diversos problemas foram identificados neste setor. Considera-se mais crítico o fato de o sistema de esteiras operar parcialmente e em fluxo descontínuo. Segundo os cooperados, o sistema nunca passou por manutenção preventiva após sua instalação. As manutenções corretivas foram diminuindo ao longo do tempo e, para funcionar plenamente, faz-se necessário um levantamento de custos para se avaliar a viabilidade financeira para manutenção, substituição do sistema ou parte dele. A falta de automação do sistema provoca descon- tinuidade do fluxo operacional, ineficiência das operações e perdas de tempo e produtividade consideráveis, além de esforços demasiados, traumas físicos e riscos de saúde para os cooperados.

O arraste manual das bolsas de fibra carregadas com os resíduos triados gera mais problemas, como a diminuição da vida útil das bolsas, risco de traumas para os cooperados, perdas de tempo e produtividade e custos operacionais desnecessários. Quanto aos resíduos não triados, descartados no final da esteira, seu recolhimento por pá manual também acarreta em perdas de tempo e riscos de trauma para os funcionários.

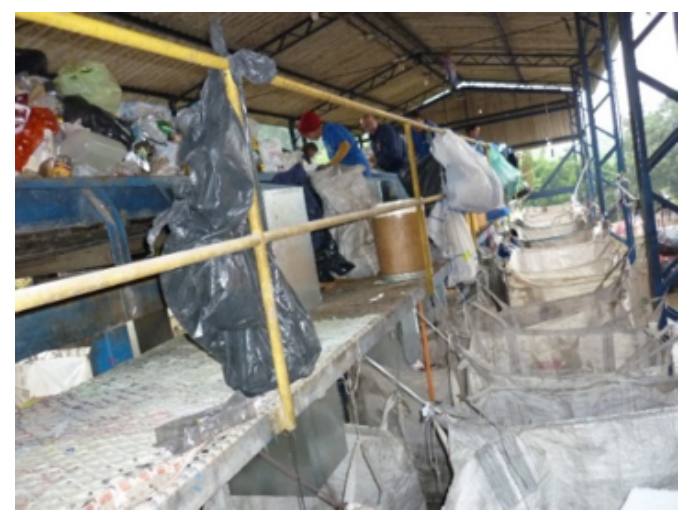

Figura 4: Bolsas para resíduos triados

Foi observado neste setor que as pessoas, em geral, não usam EPIs ou os usam de modo incorreto. Segundo a administração da cooperativa, há EPIs disponíveis, mas não há obrigatoriedade para seu uso, porque os trabalhadores se sentem incomodados com os dispositivos de proteção, um problema que pode causar acidentes de trabalho e riscos para a saúde dos cooperados.

\section{Prensagem e enfardamento}

A COOTRE opera com três prensas de resíduos, sendo que uma é exclusiva para papelões avulsos triados na pré-seleção e duas para os demais materiais triados na esteira de triagem e que devem ser comercializados prensados e enfardados. A prensa dos papelões avulsos 
está instalada no nível inferior, em local próximo à escada de acesso aos dois níveis do pavilhão. As outras duas estão instaladas no setor de estocagem. Há uma quarta prensa parada por falta de manutenção.

Os papelões triados na pré-seleção são empilhados ao lado da prensa, onde os trabalhadores abastecem manualmente o equipamento, realizam a prensagem e o posterior enfardamento. Os demais materiais separados na esteira de triagem acumulam-se nas bolsas de fibra que são arrastadas até o local das prensas. As bolsas são descarregadas manualmente no piso e do mesmo modo os materiais são alimentados nos equipamentos e depois enfardados.

No enfardamento são usadas fitas industriais resistentes. Os volumes assim constituídos são erguidos por um guindaste manual e colocados sobre carrinhos, que são empurrados manualmente até o setor de estocagem e empilhados.

Também foram identificados problemas nessas operações. A prensa de papelões está instalada em local inadequado, próximo à escada. Os papelões que se acumulam pela préseleção são em grande volume e por vezes bloqueiam a passagem entre os dois níveis, obrigando os cooperados a percorrerem um caminho alternativo mais longo e perderem tempo. As duas prensas instaladas no setor de estocagem também estão inadequadas naquele local, porque ocorre uma mistura caótica entre operações de prensagem e enfardamento, materiais espalhados no piso à espera de prensagem e fardos prontos para comercialização. Como o local tem espaço reduzido, observou-se dificuldades operacionais, como fluxos cruzados entre operações e restrições para o deslocamento dos carrinhos com fardos, o que provoca desorganização geral e desperdício de tempo no setor.

\section{Estocagem e comercialização}

O local de estocagem dos fardos consiste de um pavilhão com $609 \mathrm{~m} 2$, com duas passarelas laterais e um vão central que permite o estacionamento de apenas um caminhão para a retirada de fardos e materiais não enfardados vendidos. Este pavilhão está dividido em seis boxes, quatro dos quais armazenam os diversos materiais prontos para venda. Um dos boxes é utilizado para desmontagem de eletrodomésticos e produtos eletrônicos e classificação dos componentes, e o outro box é utilizado para a separação de resíduos recicláveis assépticos provenientes do Hospital Municipal de Esteio.

No local também há duas balanças instaladas, com capacidades para $500 \mathrm{~kg} \mathrm{e} 5 \mathrm{t}$, utilizadas na venda de materiais cujos pesos ou volumes sejam inferiores a uma carga de caminhão. Quando a carga é completa, o controle de pesagem é feito em uma balança disponibilizada pela Secretaria Municipal de Obras de Esteio e instalada em outro local, fora da COOTRE. Durante a pesquisa, constatou-se que, devido à falta de manutenção, esta balança estava inoperante e sem prazo para corrigir esta situação, obrigando a cooperativa a realizar o controle de pesagem externamente, por serviço terceirizado.

Os principais problemas identificados neste setor relacionam-se à falta de espaço para a movimentação dos fardos, devido ao uso múltiplo do local para acúmulo de materiais separados e prontos para a prensagem, triagem de resíduos hospitalares, que é feita de modo inadequado e em local impróprio, bem como o descarregamento de resíduos sólidos da coleta seletiva, realizado em dias de chuva forte.

\section{Prognóstico operacional}

\section{Estrutura física}

No geral, a estrutura física dos pavilhões está com boa adequação para as operações, sendo necessárias pequenas alterações no local. A principal ação estrutural é a colocação de um telhado com cerca de $60 \mathrm{~m} 2$ na área de chegada dos resíduos sólidos, para evitar a exposição dos cooperados às chuvas e aos raios solares e a dos materiais descarregados às chuvas. Esta ação resultaria na melhor qualidade de trabalho e no menor risco à saúde dos trabalhadores, evitaria descartes de materiais degradados por excesso de umidade (especialmente papelões) e 
acabaria com o descarregamento dos resíduos da coleta seletiva na área de estocagem e comercialização nos dias de chuva forte e seus transtornos decorrentes.

Outra ação sugerida é a ampliação do telhado no pavilhão da esteira de triagem e a substituição de uma telha quebrada. Nos dias de chuvas intensas e com ventos os trabalhadores que operam na esteira sujeitam-se às chuvas, porque a largura do telhado $(8,6 \mathrm{~m})$ é insuficiente para evitar o problema.

\section{Máquinas e equipamentos}

Para este item, sugere-se atenção para o sistema funil-esteira prévia, a esteira de triagem, as prensas e a remoção dos materiais para prensagem e estocagem.

No sistema funil-esteira prévia há dois problemas graves que devem ser solucionados. Um deles, devido à falha no projeto, é a existência de uma abertura em um lado do funil, que dá acesso ao motor da esteira prévia. Por esta abertura passa para o piso do pavilhão parte dos resíduos lançados no funil, o que provoca recolhimentos periódicos e perdas de tempo para os cooperados. Sugere-se a eliminação desta abertura, o que demandará alterações no projeto para a manutenção do motor da esteira. Porém, a situação mais crítica no sistema é a inoperância da esteira prévia, a qual deveria conduzir os resíduos do funil à esteira de triagem. Por total falta de manutenção, todo o dispositivo precisa ser substituído por um novo sistema, devido à intensa oxidação nos metais e danos na esteira, na caixa de redução, no motor e na instalação elétrica. Sugere-se que a administração da COOTRE faça um orçamento para recuperar todo este sistema e o compare a um outro orçamento que possibilite sua substituição por uma garra mecânica.

No sistema da esteira de triagem verificaram-se três problemas críticos: a liberação dos resíduos dos sacos plásticos, a manutenção operacional da esteira e os dutos de triagem. Conforme já mencionado, quem opera na esteira de triagem precisa rasgar os sacos plásticos para liberar os resíduos. Um simples dispositivo giratório com garras, na entrada da esteira, resolveria este problema, evitando-se a operação manual e perdas de tempo. Quanto à esteira, sua operação se dá de modo intermitente e limita-se a conduzir os sacos com resíduos em operações de batelada. A função de uma esteira de transporte é operar em fluxo contínuo para otimizar as operações de triagem. Na COOTRE, este fluxo não ocorre devido à falta de manutenção preventiva para melhorar o funcionamento da esteira. Quanto aos dutos de triagem, faz-se necessário aumentá-los em quantidade. Considerando o comprimento da esteira (22 m) e a variedade de resíduos triados, sugere-se sua ampliação para 28 dutos, 14 em cada lado da esteira. Entre os dutos poderiam operar na triagem até 26 cooperados. Essa modificação no sistema da esteira de triagem possibilitaria à cooperativa aumentar, consideravelmente, a massa de resíduos para reciclagem, além de melhorar os fluxos no processo e otimizar tempo operacional em relação às práticas atuais. É sugerido, também, a colocação de um container com rodas no final da esteira para armazenar os resíduos não triados e destinados ao aterro sanitário.

Quanto às prensas, recomenda-se a manutenção urgente da unidade inoperante, porque há demanda para ela. Além disso, no caso de mais uma prensa parar para manutenção, duas prensas seriam insuficientes para a atual demanda da cooperativa e geraria mais problemas. Atualmente, devido à crescente demanda de resíduos, alguns materiais são compactados manualmente, um sintoma que indica necessidade para aquisição de novas unidades, além de provocar perdas de tempo e risco de traumas físicos para os cooperados. Recomenda-se uma projeção sobre o aumento da massa de resíduos do programa Coleta Seletiva, para o melhor planejamento acerca da compra de novas prensas.

A remoção das bolsas de fibra acumuladas com resíduos triados na esteira de triagem se dá por arraste e de modo manual. Esta operação desgasta e rasga as bolsas devido à tração, ao atrito e às irregularidades do piso, dimi- 
nuindo sua vida útil e gerando custos adicionais para novas aquisições, provoca desgastes físicos e gera riscos de traumas para os cooperados e perdas de tempo. Para a solução deste problema recomenda-se a aquisição de carrinhos com pneus, sobre os quais as bolsas poderiam ser dispostas ainda vazias, especialmente para os materiais pesados, e transportadas quando cheias sem necessidade de levantamento prévio. Como alternativa, adquirir, num primeiro momento, uma quantidade de carrinhos suficiente para o transporte das bolsas com os resíduos mais pesados.

\section{Fluxograma operacional}

Para MARINHO et al. apud SANTANA \& SILVA (2010) a elaboração do layout de uma operação é de fundamental importância, uma vez que o arranjo físico determina a forma e aparência de uma operação produtiva, além de determinar o fluxo de recursos ao longo de todo o processo. Um layout mal elaborado pode gerar uma série de problemas para a operação, como: estoques desnecessários, fluxos longos ou confusos, deslocamentos extras, filas de clientes e altos tempos de produção.

CORRÊA \& CORRÊA apud SANTANA \& SILVA (2010) indicam que há, basicamente, três tipos básicos de arranjo físico, que têm características bastante específicas e apresentam diferentes potenciais de contribuírem e até alavancarem diferentes desempenhos em distintos critérios de desempenho: arranjo físico por processo, arranjo físico por produto (ou em linha) e arranjo físico posicional. Relatam que há outros tipos de arranjo físico, ditos híbridos, que procuram, de certa forma, aliar características de dois ou mais arranjos básicos, o arranjo físico celular.

Considerando as operações que a COOTRE desenvolve é sugerida a adoção de dois tipos de arranjos físicos: por produto e celular. O arranjo por processo é eficaz quando diferentes produtos passam por distintos processos, o que não é o caso da cooperativa em análise, pois todos os materiais recicláveis passam pelas mesmas operações produtivas. E o arranjo po- sicional é utilizado em casos específicos, como na construção de navios, edifícios, aeronaves, etc., onde o produto fica fixo e os trabalhadores, máquinas, equipamentos e matérias-primas se movimentam (NORÕES et al. apud SANTANA \& SILVA (2010). Ainda de acordo com estes últimos autores, o arranjo físico por produto é o tipo em que o produto se move e as máquinas ficam fixas. É a situação da COOTRE, especificamente na etapa inicial das operações de abastecimento do funil e classificação na esteira de triagem. Nesta situação, as máquinas são colocadas conforme a sequência de operações, que são executadas sem caminhos alternativos, resultando em um fluxo produtivo em linha, sem perdas de tempo.

O arranjo físico celular é sugerido para as operações de prensagem, visto que as prensas estão separadas em diferentes lugares. O agrupamento em célula, em um local específico do pavilhão, eliminaria os fluxos desnecessários de materiais e pessoas, com reflexos positivos na organização e otimização de tempos operacionais.

\section{Conclusões}

A COOTRE é uma cooperativa de reciclagem que recebe os resíduos sólidos do programa Coleta Seletiva do município de Esteio, RS. A SMMA está ampliando a coleta no programa, mas é necessário que a COOTRE esteja preparada para atender o aumento da demanda de resíduos para triagem. O diagnóstico realizado na cooperativa mostrou diversos aspectos que são críticos nas operações, processos e fluxos, os quais deverão estar compatibilizados quando a demanda de resíduos aumentar. Nas condições em que opera, já se observam dificuldades para atender a demanda atual. Se não passar por uma reestruturação, certamente a cooperativa não terá condições técnicas e operacionais para a atender à demanda futura do Coleta Seletiva.

Atualmente, a cooperativa opera com um mínimo de organização, planejamento e assessoria técnica. Como consequência, algumas atividades geram fluxos operacionais confusos 
porque são aplicados métodos que levam a um baixo rendimento e perdas de tempo. Também faltam equipamentos e manutenções adequadas aos existentes. Além disso, os cooperados operam com um mínimo de EPIs, o que cria condições favoráveis para acidentes de trabalho e traumas físicos aos mesmos. A implantação de melhorias na COOTRE certamente resultará em melhores rendimentos operacionais e financeiros.

Os principais aspectos positivos identificados no diagnóstico foram: i) a parceria ativa entre a COOTRE e a PME, que impulsiona a reciclagem de resíduos sólidos no município e estabelece condições para atender às exigências da Lei Federal 12.305/2010, sobre a Política Nacional de Resíduos Sólidos; ii) o local das operações, Centro de Triagem de Esteio, é amplo, tem infraestrutura pública adequada e permite ampliações caso sejam necessárias às futuras demandas de ambas as instituições; iii) no geral, a infraestrutura para a reciclagem de resíduos sólidos montada pela PME e usada pela COOTRE é funcional e satisfatória, sendo necessárias algumas adequações, citadas abaixo, que não são complexas; iv) os controles administrativos na COOTRE são simples mas bem organizados, frutos de intervenções de outras parcerias privadas mantidas pela cooperativa; v) os cooperados são muito motivados para o trabalho, especialmente algumas lideranças, que procuram soluções para melhorar as operações. Durante o diagnóstico, os autores sugeriram pequenas mudanças de fluxo que foram atendidas, demonstrando que o grupo tem interesse para incorporar melhoramentos em suas atividades.

Os principais problemas identificados no diagnóstico foram: i) o local onde os resíduos da coleta seletiva são descarregados não tem cobertura de telhado, o que obriga os cooperados a trabalharem sob Sol ou chuva, com possibilidade de riscos para a saúde deles e de perdas de resíduos que se degradam com umidade excessiva; ii) em dias de chuva intensa, o descarregamento é realizado em área coberta do pavilhão de estocagem, mas os resíduos precisam ser transportados manualmente aos locais de reciclagem, gerando perdas de tempo e risco de traumas físicos aos cooperados; iii) o sistema do funil que armazena os resíduos para triagem opera sem a esteira prévia (parada por falta de manutenção), a qual deveria alimentar a esteira de triagem, obrigando os trabalhadores a realizarem uma operação de modo manual e com o uso de dispositivos inadequados, como vassouras e enxadas; iv) o deslocamento das bolsas de fibra carregadas com resíduos triados, em geral, é feito por arraste manual, causando desgaste prematuro das mesmas e risco de traumas físicos aos cooperados; v) a esteira de triagem opera com tempos reduzidos e somente conduz os resíduos à ação de triagem, por bateladas, uma operação completamente descaracterizada e de baixa produtividade; vi) a quantidade de dutos (11) instalados nos lados da esteira de triagem é inadequada para a variedade de resíduos separados (em torno de 30); vii) as prensas para compactar resíduos são inadequadas em termos de quantidade (três) e manutenção; além disso, encontram-se distribuídas em vários locais, causando operações confusas, demoradas e desnecessárias; viii) a balança para o controle de pesagem dos caminhões que retiram os produtos reciclados e enfardados encontra-se inoperante (também por problema de manutenção), obrigando a cooperativa a contratar serviço externo e confiar nos valores apresentados pela prestadora do serviço; ix) a triagem de resíduos hospitalares poderia ter um espaço exclusivo para a atividade e os cooperados envolvidos na mesma poderiam ter treinamentos mais específicos e usar EPIs mais apropriados; $x$ ) as operações gerais de reciclagem têm muitos cruzamentos confusos e desnecessários de materiais e pessoas, devido a um arranjo físico inadequado de equipamentos, modo de processos e ao layout dos pavilhões, em certas particularidades.

\section{RECOMENDAÇÕES}

O prognóstico operacional neste estudo foi proposto para que a COOTRE restabeleça as operações de modo mais adequado e apropriado para a reciclagem de resíduos sólidos em 
seu complexo operacional. Foram propostas ações de relativa baixa complexidade para melhorar a qualidade do trabalho e a performance operacional, com vistas ao aumento de produtividade. As sugestões mais simples visam corrigir os problemas mais prementes, porém há ações mais complexas, especialmente para atender o aumento na demanda de resíduos que a PME projeta para o programa Coleta Seletiva do município. Como primeiro passo, recomenda-se que os administradores da cooperativa projetem, com os representantes da PME, um plano de ações que atenda às necessidades presentes e futuras de ambas as entidades. Este plano deverá conter o aporte de recursos financeiros conforme com as estratégias estabelecidas.

A COOTRE provavelmente não terá condições para assumir os custos de sua reestruturação. As vendas dos produtos reciclados geram receitas especialmente para pagar os rendimentos dos cooperados. Também são conhecidas as dificuldades financeiras das administrações públicas em geral, na atualidade. Neste contexto, recomenda-se uma parceria mais ampla, com a entrada de entidades privadas, e até mesmo da própria população de Esteio, considerando que é de interesse coletivo a solução para o lixo gerado pelos diversos agentes sociais, industriais e comerciais. Este processo não deve demorar, porque já estão estabelecidos os novos prazos para os municípios se adequarem à Lei Federal 12.305/2010.

Tem sido um erro de estratégia operacional da COOTRE deixar de fazer manutenções preventivas nos equipamentos em geral. Recomenda-se que a administração retome um plano de manutenção para evitar que mais equipamentos fiquem parados e provoquem colapsos na produção.

Caberá aos parceiros a tarefa para priorizar ações de reestruturação da cooperativa. Mas recomenda-se que as reformas e manutenções não paralisem as operações. $\mathrm{Na}$ atual conjuntura econômica, é de se esperar dificuldades na disponibilização de recursos financeiros de imediato. Neste contexto, sugere-se uma sequência de ações que irão, aos poucos, melhorando as operações, a produtividade e a qualidade de trabalho e a saúde dos cooperados: uso obrigatório de EPIs, da cabeça aos pés; palestras e treinamento sobre procedimentos operacionais corretos em máquinas e equipamentos, dispositivos de segurança do trabalho e manuseio dos resíduos; arranjo físico otimizado e layout geral apropriado para evitar fluxos confusos ou desnecessários de materiais e pessoas; construção de um telhado na área de chegada dos resíduos trazidos pela coleta seletiva; aquisição de carrinhos para a movimentação das bolsas de fibra com os resíduos triados; manutenção das prensas em operação e aquisição de, pelo menos, mais duas prensas novas; instalação de dutos suplementares nas laterais da esteira de triagem; manutenção geral da esteira de triagem para operar em fluxo contínuo e com capacidade adequada para o fluxo de resíduos; manutenção da balança para o controle de pesagem de caminhões que carregam os materiais reciclados vendidos; manutenção geral do sistema de funil, trocando o sistema da esteira prévia ou substituindo-o por uma garra mecânica que alimente a esteira de triagem.

\section{REFERÊNCIAS}

100 DIMENSÃO, 2004 Cooperativa de Reciclagem Disponível em <https://www youtube . com/watchv=MWvXd3XIgkw $>$, acesso em junho/2015 ABNT - Associação Brasileira de Normas Técnicas. NBR 10004:2004. Resíduos sólidos - Classificação, 2004, 71p.

ANTON, D. A. Diagnóstico sobre o tratamento e a produção de materiais recicláveis da Associação de Recicladores e Catadores do Município de Esteio, RS. Trabalho de Conclusão de Curso, Unilasalle, Curso de Geografia, 2014, 25p.

ARAÚJO, A. B. Qualidade de vida no trabalho: em busca da excelência pessoal e organizacional. Dissertação de Mestrado. Universidade Federal do Rio Grande do Norte, PPGA, 1998. 
BANDEIRA, A. A. Indicadores de Desempenho. Rio de Janeiro: Editora QualityMark, 2010, 192p.

BRASKEM. Diagnóstico Socioambiental de Reciclagem. Disponível em http://www . braskem. com.br/reciclagem/ diagnosticosocioambiental.pdf, acesso em junho/2015.

CALLADO, A. L. C., CALLADO, A. A. C., ALMEIDA, M. A. A utilização de indicadores de desempenho não-financeiros em organizações agroindustriais: um estudo exploratório. Organizações Rurais \& Agroindustriais, Lavras, 10(1), 2008, p. 35-48.

COOPERCATA Cooperativa de Catadores. Disponível em https://www. youtube. com/watch?v=aIEfwi9KcAU, acesso em junho/2015.

COORETA Cooperativa de Reciclagem Tatuí. Disponível em <https://www. youtube. $\mathrm{com} /$ watch?v=q1F2EA8FQcY $>$, acesso em junho/2015

COSTA R. S., JARDIM E. G. M. As Cinco Principais Dimensões do Diagnóstico Operacional NET, Rio de Janeiro, 2010. Disponível em <http://www.trilhaprojetos. com.br>, acesso em maio/2015.

HEIDEN, A. I. V. D. Cooperativas de reciclagem de lixo e inclusão social: o caso do município de Itaúna, MG. Dissertação de Mestrado. Universidade do Estado de Minas Gerais, Fundação Educacional de Divinópolis, 2008, 94p.

IBGE Instituto Brasileiro de Geografia e Estatística. Rio Grande do Sul - Esteio. Disponível em <http://cod.ibge.gov.br/23B9K>, acesso em maio/2015.

INSTITUTO 5 ELEMENTOS. Diagnóstico da Gestão dos Resíduos Sólidos Domiciliares na Subprefeitura Lapa. Prefeitura de São Paulo. Coordenação geral Mônica Pilz Borba. FEMA-SP, 2014, 106p.
ITCP-FGV. Incubadora Tecnológica de Cooperativas Populares - Fundação Getúlio Vargas. Diagnóstico de Cooperativas de Catadores PE. Plano de Negócios Inclusivos, 2012, 40p.

KARDEC, A., FLORES, J., SEIXAS, E. Gestão Estratégica e Indicadores de Desempenho. Coleção Manutenção. $2^{a}$ ed. Rio de Janeiro: QualityMark, 2009, 136p.

LIMA, A. D., HORÁCIO, S. H. A questão do lixo em Barretos. Disponível em <http://www.cdcc.usp.br/ciencia/ artigos/art_28/agua8.html>, acesso em junho/2015.

MENEZES, T. M., GUIMARÃES, M. G., SELLITTO, M. A. Medição de indicadores logísticos em duas operações de montagem abastecidas por cadeias de suprimentos. Florianópolis: Revista Produção On-line, 8(1), 2008, p. 1-23.

MÜLLER, C. J. Planejamento Estratégico, Indicadores e Processos - Uma Integração Necessária. São Paulo: Atlas, 2014, 140p.

NASCIMENTO, S., BORTOLUZZI, S. C., DUTRA, A., ENSSLIN, S. R. Mapeamento dos indicadores de desempenho organizacional em pesquisas da área de Administração, Ciências Contábeis e Turismo no período de 2000 a 2008. Revista de Administração da Universidade de São Paulo, 46(4), 2011, p. 373-391.

NOSSA TERRA. Contagem regressiva para cumprir a Política de Resíduos. Disponível em <http:// nossaterra.folhadaregiao.com.br/2013/ 08/contagem-regressiva-para-cumprir . html> , acesso em junho/2015.

PROCHNOW, T. R, ROSSETTI, J. Resíduos sólidos: coleta seletiva e Educação Ambiental na cidade de Esteio - RS, Brasil. Ambiente E Educação, 15(2), 2010, p. 197-208.

PROJETO CRIAR. Centro de Reciclagem, Inovação, Aprendizagem e Renovação. Disponível em <https://www. youtube.com/watch? $\mathrm{v}=7$ UueDWmSwcA $>$, acesso em junho/2015. 
SANTANA, J. A. S., SILVA, C. E. Modelo de Layout de Sistema Produtivo para Usinas de Reciclagem de Resíduos Inorgânicos Sólidos para Pequenos Municípios. Revista Ibero-Americana de Ciências Ambientais, Aracaju, 1, 2010, p. 68-90.

SANTOS, I. F., ROSA, J. J., ALBINO, A. M. A., PIRES, M. S. G., SANTOS, C. Avaliação da Estrutura e Organização de Cooperativas de Reciclagem de Resíduos Urbanos no Município de Campinas - SP. $2^{\circ}$ Fórum Internacional de Resíduos Sólidos, 2009.

SILVA, C. R. M., SILVA, A., RUSSO, S. M. E., OLIVEIRA, E. A. A. Q., SANTOS, V. S., QUINTAIROS, P. C. R. Cooperativas de Reciclagem de Lixo: Um estudo sobre a parceria entre uma associação de catadores e uma instituição pública. 2009. In: XIII Encontro Latino Americano de Iniciação Científica e IX Encontro Latino Americano de PósGraduação, Universidade do Vale do Paraíba. Anais eletrônicos, 2009, p. 01-05.

SIQUEIRA, I. P. Indicadores de Desempenho de Processos de Planejamento. Rio de Janeiro: Editora QualityMark, 2010, 192p.

VIEIRA, A. J. N. L., MARONI, B. C., ALBUQUERQUE F. P., BESEN, G. R., SANTOS, L. Y. B., LOPES, L., CARDO, M. B. Movimento Nacional de Catadores de Materiais Recicláveis. Do lixo à cidadania: guia para a formação de cooperativas de catadores de materiais recicláveis. PINHEL, J. R. (Org). São Paulo: Peirópolis, 2013. 